\title{
Cross-sectional study for the clinical application of extracorporeal membrane oxygenation in Mainland China, 2018
}

Wei Cheng ${ }^{1+}$, Xu-Dong Ma ${ }^{2+}$, Long-Xiang Su ${ }^{1+}$, Huai-Wu He ${ }^{1}$, Lu Wang ${ }^{1}$, Bo Tang ${ }^{1}$, Wei Du ${ }^{1}$, Yuan-kai Zhou ${ }^{1}$, Hao Wang ${ }^{1}$, Na Cui', Yun Long ${ }^{1}$, Da-Wei Liu', Yan-Hong Guo², Ye Wang ${ }^{3}$, Guang-Liang Shan ${ }^{3}$, Xiang Zhou ${ }^{1 *} \mathbb{D}$, Shu-Yang Zhang ${ }^{4}$ and Yu-Pei Zhao ${ }^{5}$

\begin{abstract}
Background: To investigate the epidemiology and in-hospital mortality of veno-venous ( $W$ ) and veno-arterial (VA) extracorporeal membrane oxygenation (ECMO) in Mainland China throughout 2018.

Methods: Patients supported by ECMO from 1700 tertiary hospitals in 31 provinces from January 1 to December 31, 2018, were selected from the National Clinical Improvement System database.

Results: The 1700 included hospitals had 2073 cases of ECMO in 2018, including 714 W and 1359 VA ECMOs. The average patient age was 50 years (IQR 31-63), and 1346 were male. The average hospital stay was 17 days (IQR 730 ), and the average costs per case was $\$ 36,334$ (IQR 22,547-56,714). The three provinces with the highest number of ECMO cases were Guangdong, Beijing, and Zhejiang; the southeast coastal areas and regions with higher GDP levels had more cases. Overall in-hospital mortality was $29.6 \%$. Mortality was higher among patients who were male, over 70 years old, living in underdeveloped areas, and who were treated during the summer. Mortality in provinces with more ECMO cases was relatively low. The co-existence of congenital malformations, blood system abnormalities, or nervous system abnormalities increased in-hospital mortality.
\end{abstract}

Conclusions: Mortality and medical expenses of ECMO among patients in China were relatively low, but large regional and seasonal differences were present. Risk factors for higher in-hospital mortality were older age, male sex, in underdeveloped areas, and treatment during the summer. Additionally, congenital malformations and blood system and nervous system abnormalities were associated with in-hospital mortality.

Keywords: Extracorporeal membrane oxygenation, Epidemiology, Mortality, Complication, China

\footnotetext{
*Correspondence: zx_pumc@163.com

†Wei Cheng, Xu-Dong Ma and Long-Xiang Su contributed equally to this work.

'Department of Critical Care Medicine, Peking Union Medical College

Hospital, Chinese Academy of Medical Sciences, 1 Shuaifuyuan, Dongcheng District, Beijing, China

Full list of author information is available at the end of the article
}

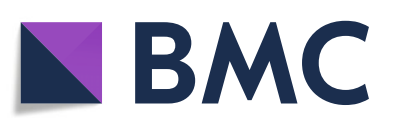

(- The Author(s). 2020 Open Access This article is licensed under a Creative Commons Attribution 4.0 International License, which permits use, sharing, adaptation, distribution and reproduction in any medium or format, as long as you give appropriate credit to the original author(s) and the source, provide a link to the Creative Commons licence, and indicate if changes were made. The images or other third party material in this article are included in the article's Creative Commons licence, unless indicated otherwise in a credit line to the material. If material is not included in the article's Creative Commons licence and your intended use is not permitted by statutory regulation or exceeds the permitted use, you will need to obtain permission directly from the copyright holder. To view a copy of this licence, visit http://creativecommons.org/licenses/by/4.0/. The Creative Commons Public Domain Dedication waiver (http://creativecommons.org/publicdomain/zero/1.0/) applies to the data made available in this article, unless otherwise stated in a credit line to the data. 


\section{Background}

Extracorporeal membrane oxygenation (ECMO) was first used in neonates in the 1970s. ECMO has been widely used to treat various types of acute cardiogenic shock and respiratory failure among adults in whom conventional life support has failed. In recent years, an increasing number of patients with severe conditions have benefited from ECMO [1, 2]. Extracorporeal life support technology has developed rapidly worldwide. From 2002 to 2012, the Extracorporeal Life Support Organization (ELSO, Ann, Arbor, MI, USA) registered 2699 cases of veno-arterial (VA) ECMO [3]; in the subsequent 5 years, this number increased to more than 5000 cases [4]. In Asia, there were 5263 cases of VA ECMO in Japan alone between 2010 and 2013 [5]. Because China has the largest population worldwide, the improvement of ECMO in China has clearly increased. In Mainland China [6], the number of ECMO cases and centers has increased yearly, but as of yet there has been no accurate and objective statistical data detailing the epidemiology and patient prognosis of ECMO.

The database of the National Clinical Improvement System (NCIS) of the National Health Commission of the People's Republic of China (https://ncisdc.medidata.cn/login. jsp) was designed to collect detailed ICU-level data. In 2018, the front page information of patient medical records from 1700 tertiary hospitals was first included in this database. We screened all the available information of ECMO-supported patients who were included in the database and conducted a summary analysis. This work provides a detailed nationwide epidemiological study of ECMO and its associated mortality based on real-world data in Mainland China and provides information to support and improve the use of ECMO.

\section{Methods}

\section{Patients and study design}

In the NCIS system, we searched the front page medical records of all patients from the 1700 tertiary hospitals. The inclusion criteria for patient enrollment were any of the following: (1) diagnosed with ECMO in the discharge diagnosis; (2) operation code of ECMO, 39.6500; (3) catheterization for ECMO noted in the surgical section; and (4) support, monitoring, or replacement of ECMO noted in the surgical section. At the same time, we searched the database for the incidence and type of complications, and whether the prone position was used during ECMO support.

\section{Study methods}

For all the ECMO patients, we collected all information including sex, age, place of residence, diagnosis at discharge, date of hospitalization, discharge date, hospitalization costs, and in-hospital mortality. We then identified the type of
ECMO support received by the included patients. If not clearly recorded, the type of ECMO support was determined according to the main diagnosis and operation site. For example, catheterization of the femoral and internal jugular veins was categorized as veno-venous (VV) ECMO; catheterization of the femoral vein and femoral artery or internal jugular vein and femoral artery was categorized as VA ECMO. VV ECMO was determined for patients with a primary diagnosis of acute respiratory failure, and VA ECMO for patients with cardiogenic shock or cardiac arrest.

We classified patients by age as follows: less than 14 , 14-20, 21-30, 31-40, 41-50, 51-60, 61-70, and older than 70 years. The 31 provinces/municipalities/autonomous regions of Mainland China were included in this survey (data from Hong Kong, Taiwan, and Macao were not included).

China is divided into seven geographic regions: Central China, North China, East China, South China, Northwest China, Northeast China, and Southwest China. According to its geographical regions and economic development levels, China is also divided into three economic zones: southeastern coastal areas, central inland areas, and western remote areas. The level of gross domestic product (GDP) in China can be divided into high-, middle- and low-GDP regions (eTable 1).

Four seasons were distinguished: spring is from March to May, summer from June to August, autumn from September to November, and winter from December to February.

The costs are expressed in USD, and the exchange rate between RMB and USD was based on the standard of January 1, 2018 (1 USD to 6.5063 RMB).

\section{Statistical analysis}

Normally distributed data are expressed as the mean and standard deviation and were compared using Student's $t$ test. Non-normally distributed data are presented as the median and interquartile range (IQR) and were analyzed using the non-parametric Mann-Whitney $U$ test. Categorical variables are expressed as number and percentage and were compared with the chi-square test or Fisher's exact test. Univariate and multivariate logistic regression analyses were performed successively to determine independent risk factors for in-hospital mortality, considering all variables with $P<0.05$ in the univariate analysis as significant. The results are expressed as the $P$ value and odds ratio (OR) with the $95 \%$ confidence interval (CI). IBM SPSS 23.0 software was used for all statistical analyses (IBM Corp., Armonk, NY, USA).

\section{Results}

The NCIS database included front page information of $79,668,156$ patients admitted to the 1700 tertiary 
hospitals of Mainland China in 2018, and a total of 2073 ECMO procedures were conducted, including 1359 (34.4\%) VA and 714 (65.6\%) VV ECMO procedures (eFigure 1). Dividing by the 1.395 billion residents in China in 2018, the incidence of ECMO was calculated to be $0.148 / 100,000$ inhabitants/year.

\section{Patient characteristics}

The median age of all the ECMO-supported patients was 50 years (IQR 31-63), and 1346 were male, accounting for $64.9 \%$. Children under 14 years accounted for $11.4 \%$, and most patients were between ages 41 and 70 . There were significant differences in the age composition between the VA and VV ECMO groups. Most patients who received VA ECMO were 51-60 years old (40.7\%) and most who received VV were $41-50$ or 61 70 years old $(40.6 \%$ together). The median length of hospital stay was 17 days (IQR 7, 30), with a significant difference between VV and VA ECMO (16 [IQR 7, 29] vs. $17[8,32]$ days, $P=0.036)$. The median hospitalization cost of ECMO was \$36,334 (IQR 22,54756,714 ), and VV cost less than VA ECMO ( $\$ 35,166$ vs. $\$ 39,162$ per patient, $P<0.0001$; Table 1 ).

\section{Geographic characteristics}

Except for Hainan, Qinghai, and Tibet, 28 of the 31 provinces have implemented ECMO support for hospitalized patients. More than 300 cases of ECMO were conducted in Guangdong, Beijing, and Zhejiang, whereas there were fewer than five ECMO procedures conducted in Gansu, Inner Mongolia, Ningxia, and Shanxi. The regional differences between VV and VA ECMO were roughly the same (Fig. 1 and eTable 2).

In terms of geographical area, the region with the largest number of ECMO cases was East China, accounting for $36.5 \%$. The four regions of North, East, South, and Central China together accounted for $90 \%$; the remaining three regions only accounted for $10 \%$ of the total cases (Table 2).

Table 1 Baseline characteristics of ECMO patients

\begin{tabular}{|c|c|c|c|c|c|c|c|}
\hline & \multicolumn{2}{|c|}{ VA ECMO $N=1359$} & \multicolumn{2}{|c|}{ VV ECMO N=714 } & \multirow[t]{2}{*}{$P$} & \multicolumn{2}{|c|}{ All $N=2073$} \\
\hline & $N$ & $\%$ & $N$ & $\%$ & & $N$ & $\%$ \\
\hline Sex & & & & & 0.1122 & & \\
\hline Male & 866 & 63.7 & 480 & 67.2 & & 1346 & 64.9 \\
\hline Female & 493 & 36.3 & 234 & 32.8 & & 727 & 35.1 \\
\hline Age (years) median, IQR & 51 & $31-63$ & 48 & $32-63$ & 0.1536 & 50 & $31-63$ \\
\hline Age (years) & & & & & $<0.0001$ & & \\
\hline$<14$ & 171 & 12.6 & 65 & 9.1 & & 236 & 11.4 \\
\hline $14-20$ & 54 & 3.9 & 28 & 3.9 & & 82 & 3.9 \\
\hline $21-30$ & 112 & 8.2 & 72 & 10.1 & & 184 & 8.9 \\
\hline $31-40$ & 131 & 9.6 & 104 & 14.6 & & 235 & 11.3 \\
\hline $41-50$ & 194 & 14.3 & 136 & 19.1 & & 330 & 15.9 \\
\hline $51-60$ & 277 & 20.4 & 98 & 13.7 & & 375 & 18.1 \\
\hline $61-70$ & 276 & 20.3 & 154 & 21.6 & & 430 & 20.7 \\
\hline$>70$ & 144 & 10.6 & 57 & 7.9 & & 201 & 9.7 \\
\hline Hospital stay (days) median, IQR & 16 & $7-29$ & 17 & $8-32$ & 0.0360 & 17 & $7-30$ \\
\hline Hospital stay (days) & & & & & 0.0995 & & \\
\hline $1-10$ & 455 & 33.5 & 232 & 32.5 & & 687 & 33.1 \\
\hline $11-20$ & 365 & 26.9 & 171 & 23.9 & & 536 & 25.9 \\
\hline $21-30$ & 229 & 16.9 & 114 & 15.9 & & 343 & 16.6 \\
\hline$>30$ & 310 & 22.8 & 197 & 27.6 & & 507 & 24.5 \\
\hline Overall cost (USD) median, IQR & 35,166 & $22,056-53,148$ & 39,162 & $24,130-64,491$ & $<0.0001$ & 36,334 & $22,547-56,714$ \\
\hline Overall cost (USD) & & & & & 0.0002 & & \\
\hline$<15,370$ & 190 & 13.9 & 78 & 10.9 & & 268 & 12.9 \\
\hline $15,370-$ & 389 & 28.6 & 164 & 22.9 & & 553 & 26.7 \\
\hline $30,740-$ & 348 & 25.6 & 180 & 25.2 & & 528 & 25.5 \\
\hline $46,110-$ & 432 & 31.8 & 292 & 40.9 & & 724 & 34.9 \\
\hline
\end{tabular}

ECMO extracorporeal membrane oxygenation, $W$ veno-venous, $V A$ veno-arterial, IQR interquartile range, USD US dollar $P$ value for the comparison between $\mathrm{V}$ and $\mathrm{VA}$ ECMO 


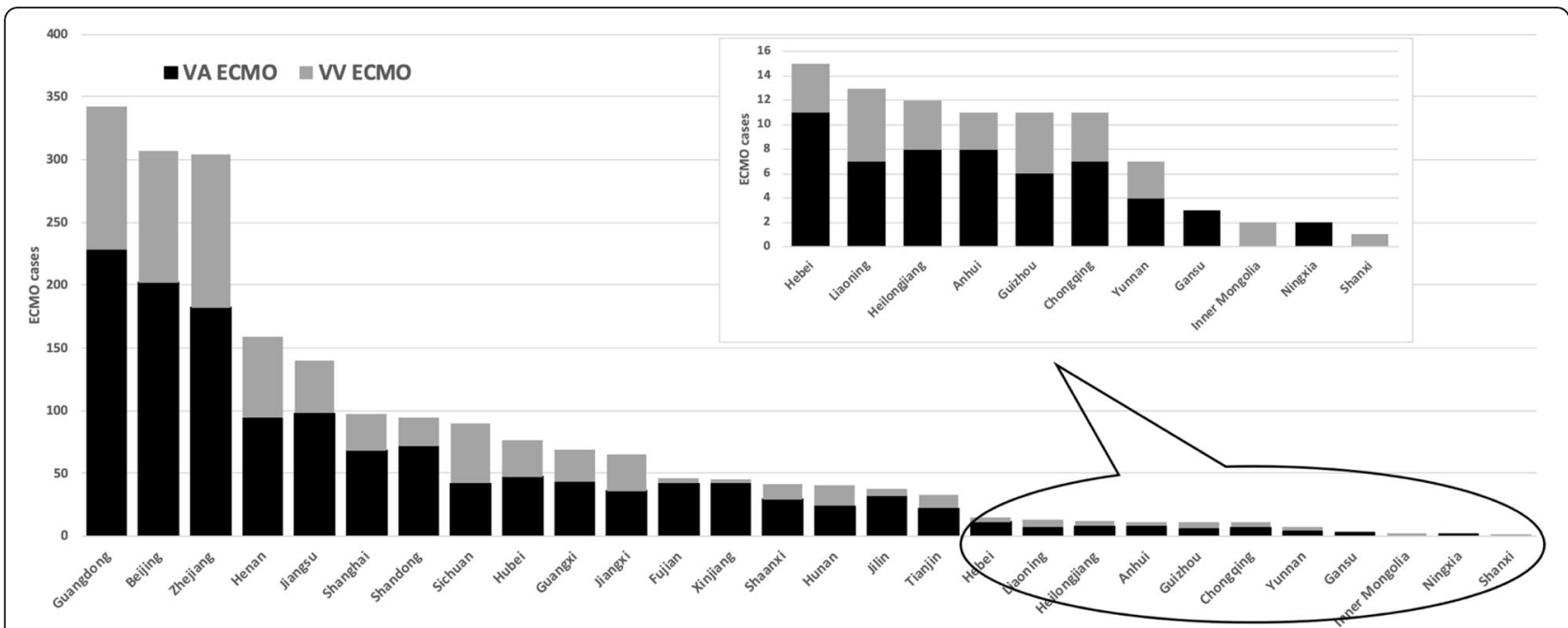

Fig. 1 Number of W and VA ECMO patients in all the provinces of China. ECMO, extracorporeal membrane oxygenation; W, veno-venous; $V A$, veno-arterial

The number of ECMO cases was significantly related to the local economic situation, which gradually decreased from the developed southeast coastal economic belt to the relatively undeveloped remote western areas and from areas with high GDP to those with low GDP (Table 2).

Through our analysis, we found a significant seasonal difference in the number of ECMO procedures. VA ECMO was mainly conducted in autumn and winter (55.1\%), and VV ECMO was mainly conducted in winter and spring (64.2\%; eFigure 2 and eTable 3).

\section{Outcomes and risk factors}

The in-hospital mortality among all ECMO patients was $29.6 \%$, with $29.9 \%$ for VA and $29.1 \%$ for VV. Additionally, the mortality rate of male patients was higher than that of females (31.2\% vs. 26.7\%). The mortality differed slightly according to age group, with a higher rate among patients between age 14-20 years and those over 70 years; the lowest mortality rate was among those aged $30-40$ years (Table 2 ).

We found large differences in in-hospital mortality for ECMO patients in different provinces, with the highest mortality reaching 53\% and the lowest being 15\% (Fig. 2 and eTable 2). The highest in-hospital mortality rates among patients receiving ECMO were in South and Southwest China (38.0\% and $37.0 \%$, respectively), and the lowest were in Northwest and Central China (22.0\% and $21.5 \%$, respectively). The in-hospital mortality of patients receiving ECMO in different economic zones and regions with different GDP levels also differed (Table 2).

The in-hospital mortality of ECMO patients across the seasons also varied. In spring and summer, the number of ECMO cases was lower and the mortality relatively higher, while in autumn and winter, the number of
ECMO cases was higher and the mortality relatively lower (eFigure 2 and eTable 3). Mortality rate for both VV and VA ECMO showed this temporal distribution.

Using the baseline data and comorbidities of ECMO patients, we performed Cox multivariate analysis to elucidate the risk factors of in-hospital mortality. ECMO performed during the summer, patients aged over 70 years, and male sex were independent risk factors for higher in-hospital mortality. Congenital malformations, blood system diseases, and neurological diseases were also independent risk factors. Residing in areas with middle-GDP levels was a protective factor (Table 3).

\section{Complications}

The most common complications during ECMO treatment were hemorrhage, infection, and mechanical complications. The proportion of bleeding complications was as high as $23.2 \%$. Infection complications occurred in $15.1 \%$ of patients receiving ECMO, with bloodstream infection accounting for 9.6\%. The incidence of ECMOrelated mechanical complications was $2.2 \%$, including blockage, accidental decannulation, and hemolysis. There were some differences in the types and incidence of complications among the different regions and among the ECMO centers (eTable 4 and eTable 5).

We also determined the number of patients treated with VV ECMO combined with the prone position. In provinces with more than 25 cases of VV ECMO, the average proportion of patients treated in the prone position was $39.5 \%$, and the highest was $83.3 \%$ (eTable 6).

\section{Discussion}

This is the first detailed nationwide epidemiologic study of ECMO and its associated mortality based on medical 
Table 2 The number of ECMO cases and in-hospital mortality in different gender, age group, geographic, and economic regions

\begin{tabular}{|c|c|c|c|c|c|c|c|}
\hline & \multicolumn{2}{|c|}{ All patients } & \multicolumn{2}{|c|}{ VA ECMO } & \multicolumn{2}{|c|}{ VV ECMO } & \multirow[t]{2}{*}{$P$} \\
\hline & $\bar{N}$ & Mortality N (\%) & $\bar{N}$ & Mortality N (\%) & $N$ & Mortality N (\%) & \\
\hline \multicolumn{8}{|l|}{ Genders } \\
\hline Male & 1346 & $420(31.2)$ & 866 & $278(32.1)$ & 480 & $142(29.6)$ & 0.339 \\
\hline Female & 727 & $194(26.7)$ & 493 & $128(25.9)$ & 234 & $66(28.2)$ & 0.523 \\
\hline \multicolumn{8}{|l|}{ Age groups } \\
\hline$<14$ & 236 & $72(30.5)$ & 171 & $52(30.4)$ & 65 & $20(30.8)$ & 0.957 \\
\hline $14-20$ & 82 & $28(34.2)$ & 54 & 19 (35.2) & 28 & $9(32.1)$ & 0.783 \\
\hline $21-30$ & 184 & $48(26.1)$ & 112 & $30(26.8)$ & 72 & $18(25.0)$ & 0.788 \\
\hline $31-40$ & 235 & $59(25.1)$ & 131 & $33(25.2)$ & 104 & $26(25.0)$ & 0.973 \\
\hline $41-50$ & 330 & 87 (26.4) & 194 & $56(28.9)$ & 136 & $31(22.8)$ & 0.218 \\
\hline $51-60$ & 375 & $115(30.7)$ & 277 & $81(29.2)$ & 98 & $34(34.7)$ & 0.314 \\
\hline $61-70$ & 430 & $131(30.5)$ & 276 & 86 (31.2) & 154 & $45(29.2)$ & 0.675 \\
\hline$>71$ & 201 & $74(36.8)$ & 144 & $49(34.0)$ & 57 & $25(43.9)$ & 0.193 \\
\hline \multicolumn{8}{|c|}{ Geographical area of China } \\
\hline East China & 757 & $195(25.8)$ & 506 & $139(27.5)$ & 251 & $56(22.3)$ & 0.126 \\
\hline South China & 411 & $156(37.9)$ & 271 & $98(36.2)$ & 140 & $58(41.4)$ & 0.297 \\
\hline North China & 358 & $120(33.5)$ & 235 & 77 (32.8) & 123 & $43(34.9)$ & 0.676 \\
\hline Central China & 275 & $59(21.5)$ & 165 & $37(22.4)$ & 110 & $22(20)$ & 0.631 \\
\hline Southwest & 119 & $44(36.9)$ & 59 & $26(44.1)$ & 60 & $18(27.3)$ & 0.112 \\
\hline Northwest & 91 & $20(21.9)$ & 76 & $16(21.1)$ & 15 & $4(26.7)$ & 0.631 \\
\hline Northeast & 62 & $20(32.3)$ & 47 & $13(27.7)$ & 15 & $7(46.7)$ & 0.170 \\
\hline \multicolumn{8}{|l|}{ Economic zones of China } \\
\hline Southeast coastal area & 1471 & $466(31.7)$ & 982 & $310(31.6)$ & 489 & $156(31.9)$ & 0.897 \\
\hline Central inland area & 403 & $88(21.8)$ & 249 & $57(22.9)$ & 154 & $31(20.1)$ & 0.514 \\
\hline Western remote area & 199 & $60(30.2)$ & 128 & $39(30.5)$ & 71 & $21(29.6)$ & 0.896 \\
\hline \multicolumn{8}{|c|}{ Different GDP level areas of China } \\
\hline High & 1441 & $441(30.6)$ & 961 & $289(30.1)$ & 480 & $152(31.7)$ & 0.536 \\
\hline Middle & 438 & $105(23.9)$ & 279 & $68(24.4)$ & 159 & $37(23.3)$ & 0.795 \\
\hline Low & 194 & $68(35.1)$ & 119 & $49(41.2)$ & 75 & $19(25.3)$ & 0.024 \\
\hline Total & 2073 & $614(29.6)$ & 1359 & $406(29.9)$ & 714 & $208(29.1)$ & 0.725 \\
\hline
\end{tabular}

ECMO extracorporeal membrane oxygenation, $W$ veno-venous, $V A$ veno-arterial, Non-surv non-survivors, mort in-hospital mortality, Mortality $N(\%)$ the number and proportion of the non-survivors; GDP gross domestic product

$P$ value for the comparison of non-survivors of the VA and VV ECMO patients

front page data in Mainland China. The data obtained in this study are authentic and can well reflect the current use and in-hospital mortality of ECMO.

Previous statistics in China [6] have shown that the number of ECMO cases has been increasing each year, as have the number of ECMO centers, which indicates that ECMO is developing rapidly. Our dataset indicated that the incidence of ECMO among the Chinese population was $0.148 / 100,000$ inhabitants/year. These data from 1700 tertiary hospitals might not include all 2018 instances of ECMO in the Mainland, as of all the 2451 tertiary hospitals that were in operation in 2018, the rest hospitals might have also performed this technique in addition to these ones, although to a much lesser extent. In a non-SARS-CoV-2 world, a reasonable figure for ECMO incidence would be $0.3-0.5 / 100,000$ if the resources are used wisely $[1,7-11]$. China still has a large gap compared with this figure. However, regarding their geographical distribution, ECMO centers have been established in many locations throughout China, showing a trend of rapid development. Owing to different levels of economic development, the improvement and proficiency of ECMO centers throughout China also varies. For example, there were 342 ECMO patients in the most developed area, whereas there was only one patient in the least developed area, which is a dramatic 


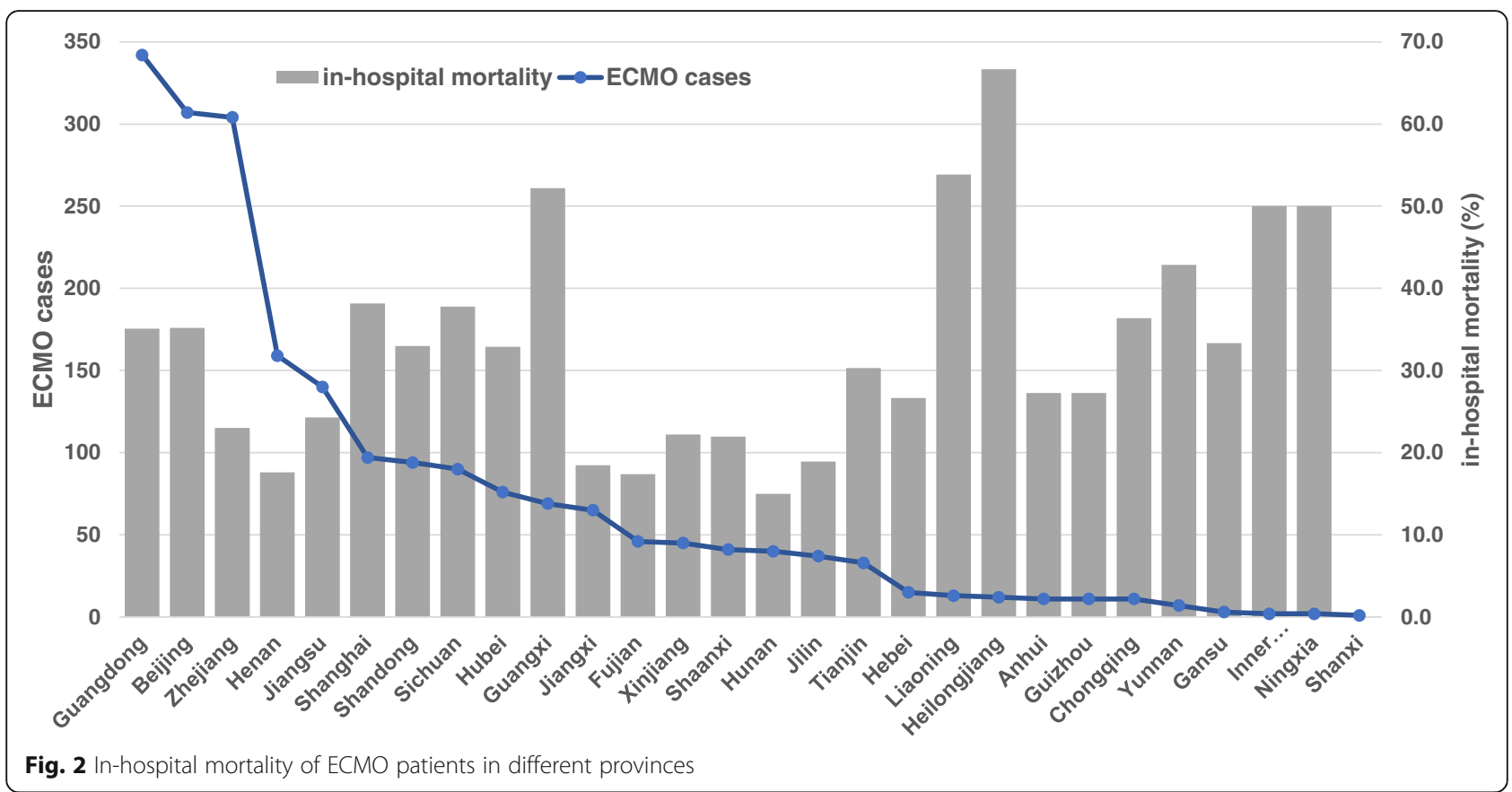

difference. In relation to this, there were also significant differences found for in-hospital mortality. Given the imbalance of medical resources, Chinese medical managers are actively organizing the introduction and implementation of ECMO-related norms and conducting ECMOrelated medical and nursing training. These measures aim to markedly improve the level of ECMO development and the patient survival rate in Mainland China.

Our data showed that the average length of hospital days on ECMO was 17 days, which is similar to that of other countries [1]. We also found that the hospital stay was significantly different between VA and VV ECMO. However, the average cost was $\$ 36,334$ (IQR 22,547-56, 714), which is significantly lower than that in other countries. A recent study showed that the average cost for patients receiving ECMO in the ICU in the US was $\$ 73,122$ for the placement procedures, with a total hospital cost of $\$ 210,100$ [12]. Unlike in many countries [1], medical insurance in China does not fully cover the costs of ECMO treatment, and patients themselves must pay a large part of the costs. Although China's GDP per capita reached $\$ 9936$ in 2018 , it was only $\$ 1594$ in remote areas with low socioeconomic levels. Eliminating the gap between the rich and poor is an important means to promote the balanced development of ECMO in China.

The mortality varied among patients who received ECMO. ELSO data from 2002 to 2012 [3] showed that the total survival-to-discharge rate of VA ECMO was $41 \%$. In 2014, the in-hospital mortalities of German patients treated with VV or VA ECMO were $58 \%$ and $66 \%$, respectively [7]. Recently, the reported overall mortality has decreased to approximately $40 \%[12,13]$ ( $35 \%$ in children) $[14,15]$. The ECMO mortality rate is also related to the type of disease, and the reported mortality for those with acute myocarditis may be as low as $25 \%$ [16]. However, the mortality rates found in large-scale epidemiological studies have all been around $60 \%$. Our data showed that the in-hospital mortality was approximately $30 \%$, which is significantly lower than that in other countries. There might be several reasons for this, listed below.

(1) Lack of data on diagnoses and the severity of illness in the medical front pages database. In terms of indications for ECMO, acute myocarditis, acute coronary disease, acute respiratory distress syndrome, and other reversible diseases are common, which would greatly reduce mortality. However, using the present dataset, we could not distinguish the specific primary disease of patients; therefore, additional data are needed for further analysis. At the same time, waiting for organ transplantation with ECMO support is not currently an indication in China.

(2) Fewer ECMO complications. Bleeding, infection, and mechanical complications were much lower in our data than those reported by some countries, especially bloodstream infections $[8,17-19]$. This could lower the mortality, as more than $10 \%$ of the causes of death could be attributed to complications. On the one hand, this might be related to the physical condition of Chinese people who generally have a smaller body size. 
Table 3 Risk factor analysis for in-hospital mortality of ECMO patients

\begin{tabular}{|c|c|c|c|c|}
\hline \multirow[t]{2}{*}{ Factors } & \multicolumn{4}{|l|}{ All } \\
\hline & $\overline{\mathrm{OR}}$ & \multicolumn{2}{|c|}{$95 \% \mathrm{Cl}$} & $P$ \\
\hline \multicolumn{5}{|l|}{ Type $(\operatorname{Ref}=\mathrm{VA})$} \\
\hline W & 0.95 & 0.75 & 1.19 & 0.6431 \\
\hline \multicolumn{5}{|l|}{ Age $(\operatorname{Ref}=0-13)$} \\
\hline $14-20$ & 1.11 & 0.62 & 1.98 & 0.7255 \\
\hline $21-30$ & 0.84 & 0.52 & 1.35 & 0.4699 \\
\hline $31-40$ & 0.80 & 0.50 & 1.27 & 0.3469 \\
\hline $41-50$ & 0.87 & 0.56 & 1.34 & 0.5280 \\
\hline $51-60$ & 1.13 & 0.74 & 1.71 & 0.5823 \\
\hline $61-70$ & 1.12 & 0.74 & 1.70 & 0.5782 \\
\hline$>71$ & 1.61 & 1.01 & 2.55 & 0.0452 \\
\hline \multicolumn{5}{|l|}{ Sex (Ref = male) } \\
\hline Female & 0.80 & 0.65 & 0.99 & 0.0400 \\
\hline \multicolumn{5}{|l|}{ GDP (Ref = high) } \\
\hline Middle & 0.72 & 0.56 & 0.93 & 0.0110 \\
\hline Low & 1.19 & 0.86 & 1.66 & 0.3017 \\
\hline \multicolumn{5}{|l|}{ Season (Ref = spring) } \\
\hline Summer & 1.35 & 1.01 & 1.81 & 0.0420 \\
\hline Autumn & 0.92 & 0.69 & 1.22 & 0.5658 \\
\hline Winter & 1.10 & 0.84 & 1.46 & 0.4858 \\
\hline \multicolumn{5}{|l|}{ Diagnosis at discharge } \\
\hline Infectious disease & 1.01 & 0.79 & 1.29 & 0.9584 \\
\hline Blood system disease & 1.29 & 1.01 & 1.65 & 0.0413 \\
\hline Endocrine disease & 1.18 & 0.96 & 1.46 & 0.1221 \\
\hline CNS disease & 1.85 & 1.40 & 2.43 & $<0.0001$ \\
\hline Circulatory disease & - & - & - & - \\
\hline Respiratory disease & - & - & - & - \\
\hline Digestive disease & 1.10 & 0.88 & 1.38 & 0.3953 \\
\hline Urogenital diseases & 1.04 & 0.83 & 1.31 & 0.7348 \\
\hline Congenital malformations & 1.59 & 1.08 & 2.33 & 0.0180 \\
\hline Injury and poisoning & 1.12 & 0.83 & 1.52 & 0.4607 \\
\hline
\end{tabular}

ECMO extracorporeal membrane oxygenation, $W$ veno-venous, $V A$ venoarterial, OR odd ration, $95 \% \mathrm{Cl} 95 \%$ confidence interval, GDP gross domestic product, CNS disease central nervous disease

Furthermore, the proportion of obese people is relatively low, which makes the procedure much smoother and results in fewer complications during ECMO maintenance. Of course, this requires analysis of more specific indicators, such as the body mass index. On the other hand, hospitals conducting ECMO in China are all ECMO centers in each province, and in most centers the procedures are performed and maintained by specialized medical teams. It has been more than 10 years since the first ECMO was performed in
China. As treatment has become more sophisticated, centers have gained much more experience. Our results were consistent with those of several large randomized controlled studies conducted in ECMO centers, all showing lower mortality rates $[2,16,20]$.

(3) More stringent indications. ECMO is not fully covered by national insurance at present; therefore, ECMO candidates are thoroughly evaluated by clinicians, which potentially led to selection bias. Furthermore, family members may be reluctant to authorize this procedure. We found that the median age of ECMO patients was 50 years, and fewer than one third were over 60. In Germany, $50 \%$ of ECMO patients in 2014 were over 60 [7]. Numerous studies have reported that age is significantly correlated with mortality [1, 5, 7]; a lower age undoubtedly improves the survival rate of the patients.

(4) A high level of care. The establishment and maintenance of ECMO reflects the overall medical level of a hospital, which is highly valued by clinicians and hospital managers. For VV ECMO patients, the proportion of patients treated in the prone position might be as high as $30 \%$, and this might be greater than $80 \%$ in certain centers. This more aggressive and advanced treatment could also reduce the mortality rate.

(5) Dying at home. The traditional preference of many Chinese people is to die at home. Some patients without hope of further treatment would choose not to die in the hospital. This information is not reflected in the front page of medical records, but it might be reflected in the ECMO mortality rate.

As to additional study findings, the risk of in-hospital mortality was significantly increased in patients older than 70 years, which is consistent with the conclusions of several studies $[1,5,7]$. Seasonal variation in mortality was also identified in this study. The number of ECMO procedures was found significantly different in different seasons, and the proficiency of medical staff might cause this difference in mortality. There might be multiple other complex reasons for these variations [21], and additional data are needed to further analyze of this finding. We also found that blood system and nervous system abnormalities increased the risk of in-hospital mortality, which might be related to hemorrhage, thrombosis, or central nervous system complications [18, 22]. Although we were unable to clearly illustrate such relationships using the existing data, the incidence of bleeding and thrombosis complications were similar to those found in previous studies [23]. 


\section{Limitations}

This is the first study of ECMO based on objective data in Mainland China. Although the data are objective and detailed, some limitations remain that are directly related to the structural features of the database used. First, the disease categories were not sufficiently detailed to distinguish the survival rate for specific diseases after ECMO support. In the future, further division according to different disease types will help to clarify the effect of ECMO treatment and its most appropriate uses. Second, Smith and El Sibai both found that the treatment duration of ECMO was significantly correlated with inhospital mortality $[1,3,7]$. We failed to reach a similar conclusion owing to limitations in the data acquisition. In future studies, we hope to include this information. Finally, because this was a retrospective study, it could not be determined whether some cases had complications owing to a lack of sufficient detail in the database. The actual consequences of complications must be further distinguished and perhaps analyzed using a prospective study design.

\section{Conclusions}

ECMO technology is developing rapidly in Mainland China, but a large gap remains in comparison with other countries. From the data analysis, in-hospital mortality was relatively high in older male patients, patients from less-developed areas, and in those treated during the summer. The presence of congenital malformations and abnormalities of the blood and nervous systems also showed increased in-hospital mortality. The large regional and seasonal differences could be because ECMO development in China is uneven. China is in the early stages of ECMO use. Therefore, standardized ECMO training and treatment procedures should be established in China to further improve the use of ECMO.

\section{Supplementary information}

Supplementary information accompanies this paper at https://doi.org/10. 1186/s13054-020-03270-1.

\section{Additional file 1: eTable 1 regional division of China.doc. \\ Additional file 2: eTable 2 the number of ECMO cases and in-hospital} mortality in all provinces in mainland China.doc.

Additional file 3: eTable $\mathbf{3}$ the number of ECMO cases and in-hospital mortality in different months.

Additional file 4: eTable 4 ECMO related complications in 7 geographical regions of China.

Additional file 5: eTable $\mathbf{5}$ ECMO related complications in provinces with more than 50 cases.

Additional file 6: eTable $\mathbf{6}$ The number and proportion of patients treated with prone position in the provinces with more than 25 cases of W ECMO.

Additional file 7: eFigure 1 Supplement 2 Flow chart of enrollment. ECMO extracorporeal membrane oxygenation; $W$ veno-venous; $V A$ venoarterial.
Additional file 8: eFigure 2 the number of ECMO cases and in-hospital mortality in different months ECMO extracorporeal membrane oxygenation; W veno-venous; VA veno-arterial.

\section{Abbreviations}

W and VA ECMO: Veno-venous and veno-arterial extracorporeal membrane oxygenation, respectively; IQR: Interquartile range; OR: Odds ratio; 95\%

Cl: Confidence interval; GDP: Gross domestic product; ELSO: The

Extracorporeal Life Support Organization; ICU: Intensive care unit;

RMB: Chinese money renminbi; USD: US dollar

\section{Authors' contributions}

$X Z$, WC, XDM, and LXS contributed to the conception of the study, data interpretation, and drafted the manuscript. YW and GLS contributed to the data collection and data analysis. HWH, LW, BT, WD, YKZ, HW, NC, YL, DWL, and $\mathrm{YHG}$ contributed to data collection and interpretation and critically revised the manuscript for important intellectual content. All authors approved the final version of the manuscript.

\section{Funding}

Funded by the National Key R\&D Plan "Public Security Risk Prevention and Control and Emergency Technical Equipment" (ID 2020YFC0861000)

Availability of data and materials

Please contact the authors for data requests.

Ethics approval and consent to participate

This study only analyzed pre-existing non-identified data from an international registry; thus, no ethics approval was required. Similarly, no patient consent was required. The data collection was approved by the National Health Commission of China.

\section{Consent for publication}

$\mathrm{N} / \mathrm{A}$

Competing interests

The authors declare that they have no competing interests.

\section{Author details}

${ }^{1}$ Department of Critical Care Medicine, Peking Union Medical College Hospital, Chinese Academy of Medical Sciences, 1 Shuaifuyuan, Dongcheng District, Beijing, China. ${ }^{2}$ Department of Medical Administration, National Health Commission of the People's Republic of China, Beijing 100044, China. ${ }^{3}$ Department of Epidemiology and Biostatistics, Institute of Basic Medicine Sciences, Chinese Academy of Medical Sciences (CAMS) \& School of Basic Medicine, Peking Union Medical College, Beijing 100730, China. ${ }^{4}$ Department of Cardiology, Peking Union Medical College Hospital, Chinese Academy of Medical Sciences, 1 Shuaifuyuan, Dongcheng District, Beijing, China. ${ }^{5}$ Department of General Surgery, Peking Union Medical College Hospital, Chinese Academy of Medical Sciences, 1 Shuaifuyuan, Dongcheng District, Beijing, China.

Received: 16 April 2020 Accepted: 2 September 2020

Published online: 11 September 2020

\section{References}

1. El Sibai R, Bachir R, El Sayed M. ECMO use and mortality in adult patients with cardiogenic shock: a retrospective observational study in U.S. hospitals. BMC Emerg Med. 2018;18(1):20.

2. Combes A, Hajage D, Capellier G, Demoule A, Lavoue S, Guervilly C, Da Silva $D$, Zafrani $L$, Tirot $P$, Veber $B$, et al. Extracorporeal membrane oxygenation for severe acute respiratory distress syndrome. N Engl J Med. 2018;378(21): 1965-75.

3. Smith $M$, Vukomanovic A, Brodie D, Thiagarajan R, Rycus $P$, Buscher $H$ Duration of veno-arterial extracorporeal life support (VA ECMO) and outcome: an analysis of the extracorporeal life support organization (ELSO) registry. Crit Care. 2017;21(1):45

4. Organization ELS: ECMO and ECLS > Registry > Statistics > International summary. 2016. https://www.elso.org/Registry/Statistics/InternationalSummary.aspx. 
5. Aso S, Matsui H, Fushimi K, Yasunaga H. In-hospital mortality and successful weaning from venoarterial extracorporeal membrane oxygenation: analysis of 5,263 patients using a national inpatient database in Japan. Crit Care. 2016;20:80.

6. Yu HXLCJ. China statistics of extracorporeal life support in 2017. Natl Med J China. 2018;98(44):3603-6.

7. Karagiannidis C, Brodie D, Strassmann S, Stoelben E, Philipp A, Bein T, Muller T, Windisch W. Extracorporeal membrane oxygenation: evolving epidemiology and mortality. Intensive Care Med. 2016;42(5):889-96.

8. Lafçı G, Budak AB, Yener AÜ, Cicek OF. Use of extracorporeal membrane oxygenation in adults. Heart, Lung Circ. 2014;23(1):10-23.

9. Sauer CM, Yuh DD, Bonde P. Extracorporeal membrane oxygenation use has increased by 433\% in adults in the United States from 2006 to 2011. ASAIO J. 2015;61(1):31-6.

10. Natt BS, Desai H, Singh N, Poongkunran C, Parthasarathy S, Bime C. Extracorporeal membrane oxygenation for ARDS: national trends in the United States 2008-2012. Respir Care. 2016;61(10):1293-8.

11. ELSO: https://www.elso.org/Registry/Statistics/InternationalSummary.aspx. Accessed 27 July 2020.

12. Harvey MJ, Gaies MG, Prosser LA. U.S. and international in-hospital costs of extracorporeal membrane oxygenation: a systematic review. Appl Health Econ Health Policy. 2015;13(4):341-57.

13. Oude Lansink-Hartgring A, Dos Reis MD, Donker DW, Maas JJ, Delnoij T, Kuijpers M, van den Brule J, Scholten E, Endeman H, Vlaar APJ, et al. Costeffectiveness in extracorporeal life support in critically ill adults in the Netherlands. BMC Health Serv Res. 2018;18(1):172.

14. Fletcher K, Chapman R, Keene S. An overview of medical ECMO for neonates. Semin Perinatol. 2018;42(2):68-79.

15. Jenks CL, Raman L, Dalton HJ. Pediatric extracorporeal membrane oxygenation. Crit Care Clin. 2017;33(4):825-41.

16. New Zealand Australia Extracorporeal Membrane Oxygenation Influenza Investigators DA, Jones D, Bailey M, Beca J, Bellomo R, Blackwell N, Forrest P, Gattas D, Granger E, Herkes R, Jackson A, McGuinness S, Nair P, Pellegrino V, Pettila V, Plunkett B, Pye R, Torzillo P, Webb S, Wilson M, Ziegenfuss M. Extracorporeal membrane oxygenation for 2009 influenza $A(H 1 N 1)$ acute respiratory distress syndrome. JAMA. 2009;302:1888-95.

17. Biffi S, Di Bella S, Scaravilli V, Peri AM, Grasselli G, Alagna L, Pesenti A, Gori A. Infections during extracorporeal membrane oxygenation: epidemiology, risk factors, pathogenesis and prevention. Int J Antimicrob Agents. 2017;50(1):9-16.

18. Murphy DA, Hockings LE, Andrews RK, Aubron C, Gardiner EE, Pellegrino VA, Davis AK. Extracorporeal membrane oxygenation-hemostatic complications. Transfus Med Rev. 2015;29(2):90-101.

19. Biancari F, Perrotti A, Dalen M, Guerrieri M, Fiore A, Reichart D, Dell'Aquila AM, Gatti G, Ala-Kokko T, Kinnunen EM, et al. Meta-analysis of the outcome after postcardiotomy venoarterial extracorporeal membrane oxygenation in adult patients. J Cardiothorac Vasc Anesth. 2018;32(3):1175-82.

20. Menon N, Perez-Velez CM, Wheeler JA, Morris MF, Amabile OL, Tasset MR, Raschke RA. Extracorporeal membrane oxygenation in acute respiratory distress syndrome due to influenza A (H1N1)pdm09 pneumonia. A singlecenter experience during the 2013-2014 season. Rev Bras Ter Intensiva. 2017;29(3):271-8.

21. Stewart S, Keates AK, Redfern A, McMurray JJV. Seasonal variations in cardiovascular disease. Nat Rev Cardiol. 2017;14(11):654-64.

22. Xie A, Lo P, Yan TD, Forrest P. Neurologic complications of extracorporeal membrane oxygenation: a review. J Cardiothorac Vasc Anesth. 2017;31(5): $1836-46$.

23. Uddin IRDTAZF. The role and impact of extracorporeal membrane oxygenation in critical care. Methodist Debakey Cardiovasc J. 2018;14(2): $110-9$.

\section{Publisher's Note}

Springer Nature remains neutral with regard to jurisdictional claims in published maps and institutional affiliations.

Ready to submit your research? Choose BMC and benefit from:

- fast, convenient online submission

- thorough peer review by experienced researchers in your field

- rapid publication on acceptance

- support for research data, including large and complex data types

- gold Open Access which fosters wider collaboration and increased citations

- maximum visibility for your research: over $100 \mathrm{M}$ website views per year

At BMC, research is always in progress.

Learn more biomedcentral.com/submissions 